\title{
Effects of Maternal Undernutrition During Late Gestation on the Lung Surfactant System and Morphometry in Rats
}

\author{
CHUNG-MING CHEN, LENG-FANG WANG, AND BORCHERNG SU \\ Department of Pediatrics [C.-M.C.], Taipei Medical University Hospital, Taipei 110, Taiwan, and \\ Department of Biochemistry [L.-F.W., B.S.], School of Medicine, Taipei Medical University,
}

Taipei 110, Taiwan

\begin{abstract}
ABS
Intrauterine growth restriction (IUGR) is associated with
reduced lung function during infancy and throughout adulthood.
We investigated the effects of maternal undernutrition (50\%
rations of the control food intake) during the last week of
gestation on the pulmonary surfactant system and lung mor-
phometry in postnatal rats. IUGR rats exhibited a significantly
lower body weight, lower lung weight, lower lung/body weight
ratio, lower lung volume, and lower lung volume/body weight
ratio on some postnatal days. IUGR rats had a significantly lower
lung saturated phosphatidylcholine and lower plasma corticoste-
rone levels on postnatal d 1 only, and values were comparable
between control and IUGR rats in the ensuing weeks. Lung
surfactant protein (SP)-A, SP-B, SP-C, and SP-D mRNA expres-
sions were similar between control and IUGR rats. Volume
fractions of the alveolar airspace were significantly lower in
IUGR rats on postnatal d 7, 14, and 42. Alveolar surface areas
were significantly lower in IUGR rats during the study period.
\end{abstract}
IUGR has been shown in association with reduced lung function during infancy and perhaps throughout adulthood (1-5). During the neonatal period, IUGR can increase risk of respiratory distress and death among both term and preterm infants $(1,2)$. It has been reported that IUGR is associated with reduced expiratory flow rates among children aged 5-11 y (3). Low birth weight, indicative of IUGR, has been associated with reduced lung function and increased death rates from chronic obstructive airway disease in adult life $(4,5)$. This association was independent of smoking habit and social class.

IUGR has multiple causes, including maternal undernutrition, hypertension, anemia, placental infarction, and tobacco smoking (6). IUGR fetuses tend to have hypoxemia, hypoglycemia, and elevated plasma cortisol levels $(7,8)$. Each of these factors could affect fetal lung development. Elevated cortisol

Received July 9, 2003; accepted January 22, 2004

Correspondence: Chung-Ming Chen, M.D., Department of Pediatrics, Taipei Medical University Hospital, 252 Wu Hsing St., Taipei 110, Taiwan; e-mail: cmchen@tmu.edu.tw

DOI: 10.1203/01.PDR.0000134254.83113.8E
The alveolar surface area/body weight ratio reached a peak on postnatal d 7, and values were significantly lower in IUGR rats on postnatal d $1,14,28$, and 42 . We conclude that maternal undernutrition during late gestation decreases lung surfactant lipid levels in the immediate postnatal period and alters the development of lung structure during the postnatal period. Alteration of lung surfactant and structure may be important in the pathogenesis of impaired pulmonary function in IUGR infants and children. (Pediatr Res 56: 329-335, 2004)

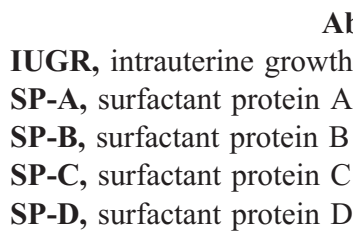

levels have been shown to enhance lung maturation (9), whereas hypoxemia and hypoglycemia have been shown to retard lung maturation $(10,11)$. We carried out this study because experiments to investigate the IUGR consequences on the pulmonary surfactant system in postnatal rats are limited in the literature. In this study, we hypothesized that maternal undernutrition-induced IUGR during late gestation would influence lung surfactant system and morphometry in the postnatal period. The aims of this study were to investigate the effects of maternal undernutrition during the last week of gestation on the rat pulmonary surfactant system and lung morphometry in the postnatal period and to clarify the mechanism underlying the impaired lung function in infancy and childhood.

\section{MATERIALS AND METHODS}

Animals. This study was approved by the Institutional Animal Use Committee at Taipei Medical University and was performed using timed pregnant Sprague-Dawley rats (vaginal 
smear positive, $\mathrm{d} 0$; term, d 22). All animals were individually caged at $22^{\circ} \mathrm{C}$, with a 12 -h light-dark cycle in an isolated room. Six control rats received food (regular rat chow containing $23.5 \%$ protein, $4.5 \%$ fat, and $53 \%$ carbohydrate) and water ad libitum from hanging containers throughout their pregnancies. Their food consumption was measured daily by weighing the container after carefully collecting spilled chow. The four experimental animals (maternal undernutrition) consisted of an age- and weight-matched group that received $50 \%$ rations of the control food intakes during their last trimester from $d$ $15-21$ of gestation.

The dams delivered spontaneously at term and were then immediately switched back to standard rat chow. The offspring were nursed by their mothers until weaning at 4 wk of age, when they were placed on standard chow. On d 1, 7, 14, 28, and 42 after birth, 6-14 rat pups from each of the five age groups were randomly selected from each of the control litters and undernourished litters, irrespective of sex, and anesthetized with an intraperitoneal injection of pentobarbital $(50 \mathrm{mg} / \mathrm{kg}$, Abbott Laboratories, North Chicago, IL, U.S.A.). No distinction regarding the sex of the animals was made because there are no differences in growth rate between sexes during the early postnatal period (12). Each newborn rat was weighed, a ventral midline incision was made, and a blood sample was taken from the heart. Pooling of serum from an entire litter was required to obtain an adequate quantity for rats delivered on postnatal d 1. Lesage et al. (13) reported that maternal undernutrition during late gestation induces fetal overexposure to maternal corticosterone. There are limited data on the effects of IUGR on the plasma corticosterone in postnatal rats. Therefore, plasma was immediately separated from blood cells by centrifugation and kept at $-20^{\circ} \mathrm{C}$ for corticosterone measurement using an enzyme immunoassay kit (Diagnostic Systems Laboratories Inc., Webster, TX, U.S.A.). Lungs were dissected free and weighed to the nearest $0.1 \mathrm{mg}$. Immediately after death, the right lung was ligated and the left lung was fixed by tracheal instillation of $10 \%$ buffered formalin at a pressure of $25 \mathrm{~cm}$ $\mathrm{H}_{2} \mathrm{O}$ for $10 \mathrm{~min}$. After ligation of the left main bronchus, fixation was continued by placing the lungs in buffered formalin for $24 \mathrm{~h}$. Left lung volume was determined by fluid dis- placement (14) and extrapolated to obtain total lung volume using total lung weight. Left lungs were embedded in paraffin, cut into $4-\mu \mathrm{m}$-thick sections, and stained with hematoxylin and eosin.

Measurement of saturated phosphatidylcholine in lung tissue. Right lungs were homogenized and extracted with chloroform-methanol (15). Lipid extracts from lung homogenates were treated with osmium tetroxide, and saturated phosphatidylcholine was recovered by alumina column chromatography and quantified using a phosphorus assay $(16,17)$.

Surfactant protein gene expression by reverse transcription PCR (RT-PCR). Lung tissue ( $\sim 100 \mathrm{mg}$ ) from right lungs was ground into a powder in liquid nitrogen, and gene expressions of SP-A, SP-B, SP-C, and SP-D were measured with RT-PCR. Total RNA was extracted using the TRIzol Reagent (Invitrogen Life Technologies, Paisley, UK) according to the manufacturer's instructions. Yield and purity of the isolated RNA solution were determined by A260 and A280 readings on a spectrophotometer. Reverse transcription was performed on $3 \mu \mathrm{g}$ of RNA with an oligo-dT primers and avian myeloblastosis virus reverse transcriptase (Roche Molecular Biochemicals, Indianapolis, IN, U.S.A.). The PCR were carried out with the primers shown in Table 1 . The primer annealing temperature was $60^{\circ} \mathrm{C}$ with 28 cycles, 31 cycles, 25 cycles, 29 cycle,s and 33 cycles for SP-A, SP-B, SP-C, SP-D, and $\beta$-actin, respectively. The PCR products were analyzed by electrophoresis on an agarose gel, stained with ethidium bromide, and photographed. To determine the linear range of the PCR, the intensity of amplified products was plotted against cycle number. At least three samples on each postnatal day were analyzed in each group for each surfactant protein.

Lung morphometry. As a single lobe of the rat lung has been shown to be a representative sampling of the morphometry of the entire lung (18), two to three sections were selected from upper part of the left lung for each animal. At least two sections were used to obtain individual data. Morphometric measurements were performed blindly on the left lung by the same observer (B.S.). Lung tissues were dehydrated in alcohol, embedded in paraffin, and stained with hematoxylin and eosin. Digitized images from 10 nonoverlapping fields were captured

Table 1. Oligonucleotide sequences of the primers used

\begin{tabular}{|c|c|c|}
\hline Primer & Sequence $5^{\prime} \rightarrow 3^{\prime}$ & $\begin{array}{l}\text { Product size } \\
\quad \text { (bp) }\end{array}$ \\
\hline \multicolumn{3}{|c|}{ SP-A (accession no. M33201) } \\
\hline Sense & GGA AGC CCT GGG ATC CCT GGA & 558 \\
\hline \multicolumn{3}{|c|}{ SP-B (accession no. X14778) } \\
\hline Sense & GTT CCA CTG CAG ATG CCA TTG & 215 \\
\hline Antisense & CAT GTG CTG TTC CAC AAA CTG C & \\
\hline Antisense & TGG CTT ATA GGC GGT CAG GAG CCG CTG GTA & \\
\hline \multicolumn{3}{|c|}{ SP-D (accession no. M81231) } \\
\hline Sense & ACT TCC AGA CAG TGC TGC TCT GAG GC & 456 \\
\hline Antisense & ATA ACC AGG CGC TGC TCT CCA CAA GCC & \\
\hline \multicolumn{3}{|c|}{ (6) } \\
\hline Sense & TTG TAA CCA ACT GGG ACG ATA TGG & 764 \\
\hline
\end{tabular}


by systematic-random approaches from each lung section (i.e., 20 images per lung) using a Kodak digital camera interfaced with a Nikon microscope and an IBM-PC-compatible computer (19). Images were printed out and examined at a final magnification of $\times 400$. The number of points that fell on the alveolar airspace, alveolar wall, alveolar duct, and nonparenchyma were counted by superimposing a transparent test lattice (49 points) onto enlarged printed photographic images. We counted 980 points/rat to attain a relative error between $5 \%$ and $10 \%$ (20). Saccules, alveoli, and alveolar ducts were distinguished by size, secondary alveolar septa, and morphology. Nonparenchymal fraction includes conducting airways, blood vessels, and perivascular interstitium. The volume fraction is equal to $\mathrm{Pi} / \mathrm{Pt}$, where Pi represents the number of test points hitting the structure of interest, and $\mathrm{Pt}$ is the total number of points hitting the reference space (20). Total surface area of alveoli and alveolar ducts in a unit of lung volume (Sv) was determined using the formula $\mathrm{Sv}=2 \mathrm{I} / \mathrm{L}$, where $\mathrm{I}$ is the number of intersection points with the air-tissue interface, and $\mathrm{L}$ is the test line length within the reference volume. Alveolar wall thickness was determined as the volume per unit area of alveolar surface according to the formula AWF/Sv, where AWF is the volume fraction of alveolar wall tissue. The total alveolar surface area is equal to $\mathrm{Sv} \times \mathrm{PF} \times \mathrm{FLV}$, where $\mathrm{PF}$ (parenchymal fraction) is the volume fraction of alveoli and alveolar ducts, and FLV is the fixed lung volume.

Statistical analysis. Data are expressed as the mean \pm SEM. Between-group comparisons at each age group were made using $t$ test. Differences were considered significant at $p<$ 0.05 .

\section{RESULTS}

There were 62 fetuses from six rats in the control group and 40 fetuses from four rats in the undernourished group. There was no significant difference in litter sizes between the two study groups.

Effects of undernutrition on maternal body weight during late gestation. Body weights of undernourished rats were kept at around $400 \mathrm{~g}$ during the last 7 gestational days, and the values were significantly lower than those of control rats from gestational d 19-21 (Fig. 1).

Body weight, lung weight, and lung volume in control and IUGR rats. Effects of maternal undernutrition on postnatal body weight, lung weight, and lung volume are presented in Table 2. IUGR rats exhibited significantly lower body weights on postnatal $\mathrm{d} 1,7,14$, and 28 ; lower lung weights on postnatal $\mathrm{d} 1,7$, and 14; lower lung/body weight ratios on postnatal d 1 and 7; lower lung volume during the postnatal period; and lower lung volume/body weight ratios on postnatal d 1 and 42 when compared with control rats.

Changes in saturated phosphatidylcholine in lung tissue of control and IUGR rats. Saturated phosphatidylcholine contents in lung tissue reached a peak on postnatal $\mathrm{d} 1$ and decreased as rats aged. IUGR rats had lower saturated phosphatidylcholine levels than control rats during the study period and the value reached statistical significance on postnatal d 1 only (Fig. 2). Saturated phosphatidylcholine/total phospholipid

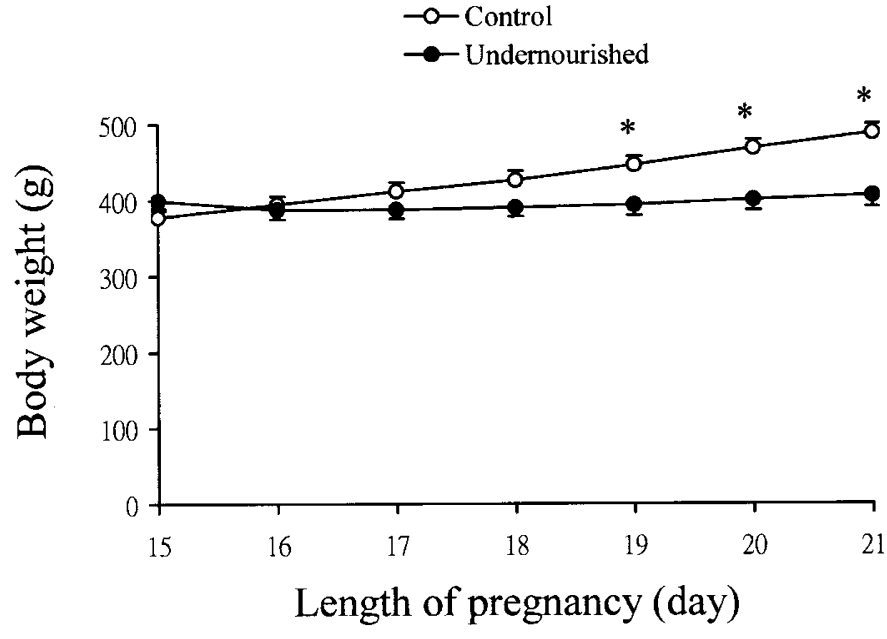

Figure 1. Body weights of control (open symbols, $n=6$ ) and undernourished (filled symbols, $n=4$ ) pregnant rats during the last 7 gestational days. Body weights of undernourished rats were significantly lower than those of controls from gestational d $19-21(* p<0.05)$.

ratios in lung tissues were comparable between control and IUGR rats (data not shown).

Plasma corticosterone levels in control and IUGR rats. The plasma corticosterone level was significantly lower in IUGR rats than in control rats on postnatal d 1 only (Fig. 3). In both groups, corticosterone concentrations increased between postnatal d 14 and 28, then decreased after postnatal d 28.

Surfactant protein gene expression in control and IUGR rats. Effects of maternal undernutrition on the expression of SP-A, SP-B, SP-C, and SP-D mRNA during the postnatal period are shown in Figure 4. The results were expressed on the basis of $\beta$-actin for each postnatal day. Lung SP-A, SP-B, SP-C, and SP-D mRNA expressions were similar between control and IUGR rats during the study period.

Effects of maternal undernutrition on lung morphometry. Light micrographs of lung sections stained with hematoxylin and eosin are illustrated in Figure 5. Alveolar wall thickness becomes progressively thinner as rats aged in both groups. Alveolar airspace areas were smaller in IUGR rats during the study period.

The volume fractions of alveolar airspace were lower in IUGR rats, and values reached statistical significance on postnatal d 7, 14, and 42 (Fig. 6A). Volume fractions of the alveolar wall, alveolar duct, and nonparenchyma were comparable between control and IUGR rats on each postnatal day. Alveolar wall thickness was comparable between control and IUGR rats (Fig. 6B). Alveolar surface area increased as rats aged, and values were significantly lower in IUGR rats during the study period (Fig. 7A). The alveolar surface area/body weight ratio reached a peak on postnatal $\mathrm{d} 7$ and decreased as rats aged for both control and IUGR rats, and values were significantly lower in IUGR rats on postnatal d 1, 14, 28, and 42 (Fig. 7B).

\section{DISCUSSION}

The effect of maternal undernutrition on the pulmonary surfactant system during the postnatal period is largely unknown. In the present study, late gestational exposure of rat 
Table 2. Body weight, lung weight, and left lung volume in control and IUGR rats

\begin{tabular}{|c|c|c|c|c|c|c|c|}
\hline & No. & $\begin{array}{l}\text { Age } \\
\text { (d) }\end{array}$ & $\begin{array}{l}\text { Body weight } \\
\text { (g) }\end{array}$ & $\begin{array}{l}\text { Lung weight } \\
\text { (g) }\end{array}$ & $\begin{array}{l}\text { Lung/body } \\
\text { weight (\%) }\end{array}$ & $\begin{array}{l}\text { Lung volume } \\
\text { (mL) }\end{array}$ & $\begin{array}{c}\text { Lung } \\
\text { volume/body } \\
\text { weight }(\%)\end{array}$ \\
\hline Control & 12 & 1 & $6.7 \pm 0.1$ & $0.13 \pm 0.00$ & $1.93 \pm 0.06$ & $0.42 \pm 0.04$ & $6.24 \pm 0.54$ \\
\hline Control & 13 & 7 & $15.4 \pm 0.8$ & $0.28 \pm 0.02$ & $1.81 \pm 0.03$ & $0.96 \pm 0.03$ & $6.36 \pm 0.35$ \\
\hline IUGR & 10 & 7 & $11.4 \pm 0.7 * *$ & $0.18 \pm 0.02 *$ & $1.58 \pm 0.05 * *$ & $0.64 \pm 0.02 * *$ & $5.45 \pm 0.26$ \\
\hline Control & 14 & 14 & $33.1 \pm 1.1$ & $0.53 \pm 0.02$ & $1.61 \pm 0.07$ & $1.60 \pm 0.04$ & $4.87 \pm 0.19$ \\
\hline IUGR & 6 & 28 & $82.8 \pm 4.5^{*}$ & $0.65 \pm 0.03$ & $0.78 \pm 0.01$ & $1.61 \pm 0.21 * *$ & $1.94 \pm 0.21$ \\
\hline Control & 9 & 42 & $189.1 \pm 5.2$ & $1.18 \pm 0.04$ & $0.62 \pm 0.01$ & $4.40 \pm 0.29$ & $2.14 \pm 0.13$ \\
\hline IUGR & 6 & 42 & $178.7 \pm 14.2$ & $1.03 \pm 0.06$ & $0.58 \pm 0.02$ & $2.92 \pm 0.39 * *$ & $1.61 \pm 0.11^{* *}$ \\
\hline
\end{tabular}

Values are the mean $\pm \mathrm{SEM} ; * p<0.05, * * p<0.01$, compared with control rats at each time point.

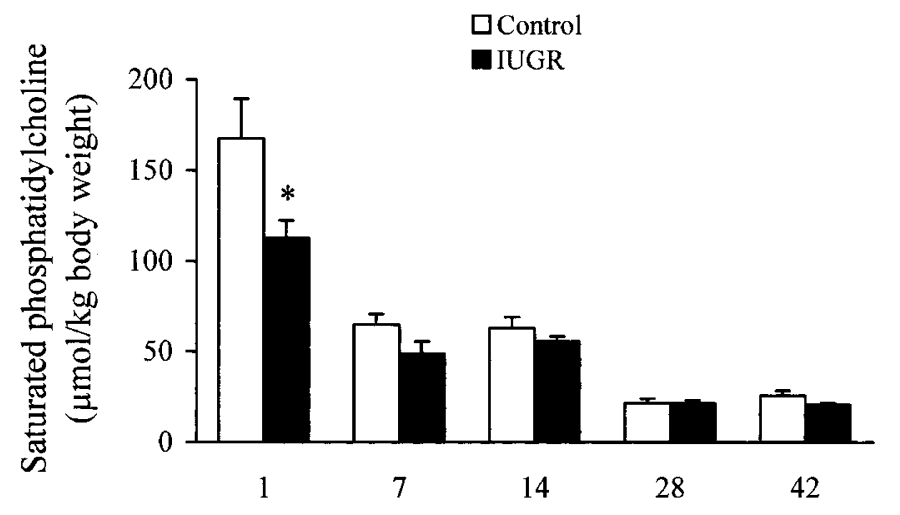

Age (day)

Figure 2. Saturated phosphatidylcholine contents of lung tissue in control and IUGR rats during the first 6 postnatal weeks. Bars are means $\pm \operatorname{SEM}(n=$ 6-9). Saturated phosphatidylcholine contents reached a peak on postnatal d 1 and decreased as the rats aged. IUGR rats had significantly lower saturated phosphatidylcholine than control rats on postnatal d $1\left({ }^{*} p<0.05\right)$. The values were comparable between control and IUGR rats in the ensuing weeks.

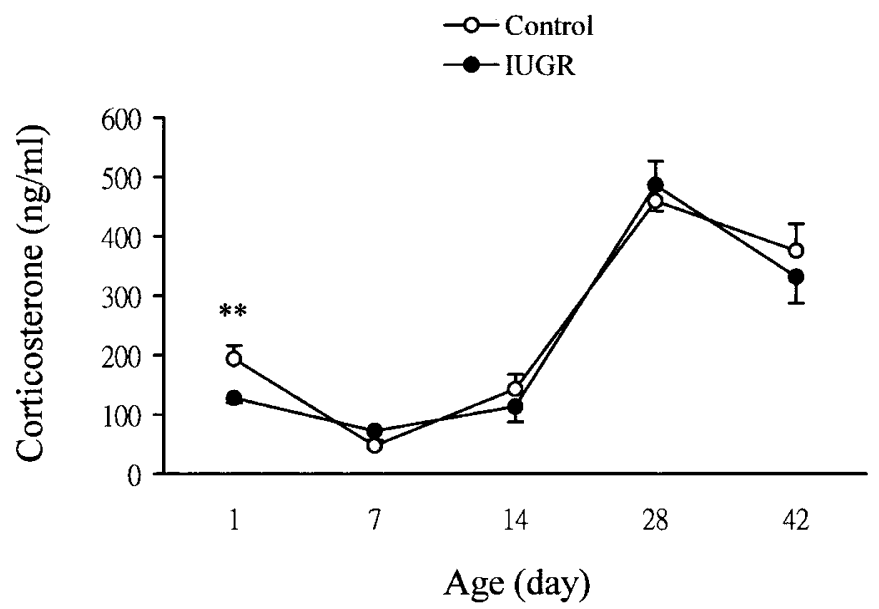

Figure 3. Plasma corticosterone levels in control (open symbols) and IUGR (filled symbols) rats. Bars are means $\pm \operatorname{SEM}(n=4-6)$. Plasma corticosterone was significantly lower in IUGR rats than in control rats on postnatal $\mathrm{d} 1(* * p$ $<0.01)$. In both groups, corticosterone concentrations increased between postnatal d 14 and 28 , then decreased after postnatal d 28 .

pups to maternal undernutrition was found to have produced changes in lung surfactant lipid levels in the immediate postnatal period and in the development of the lung structure
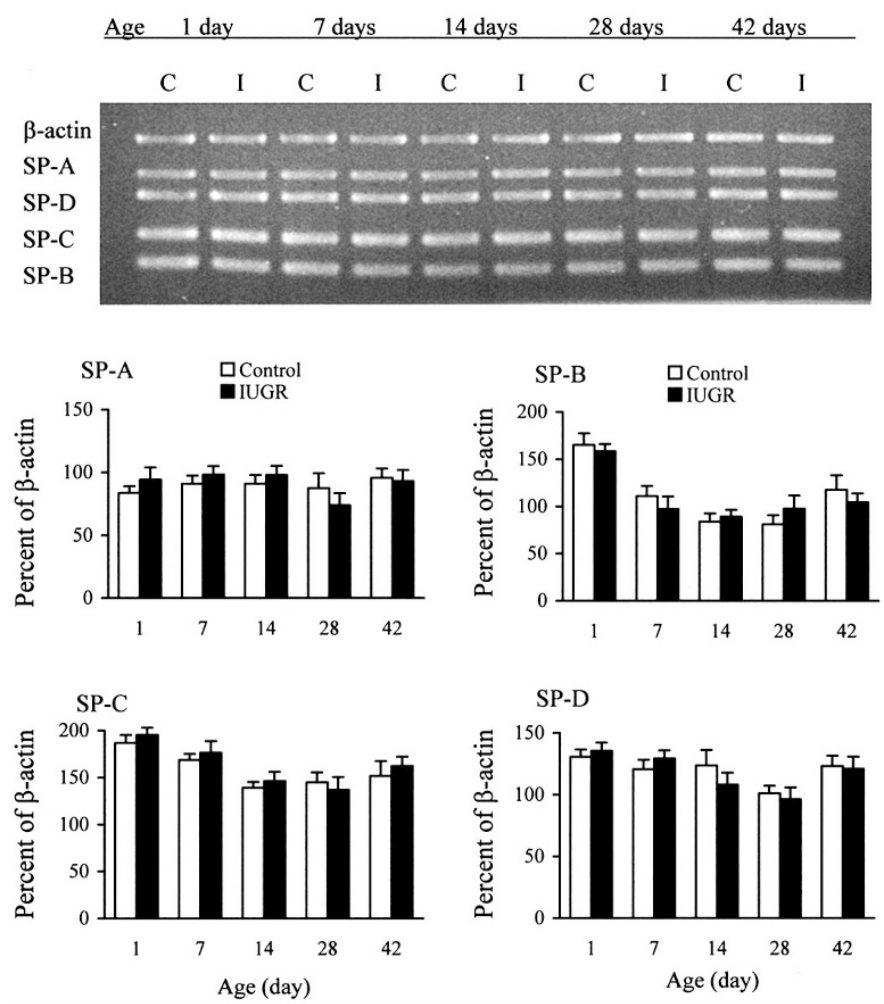

Figure 4. Effects of maternal undernutrition on mRNAs encoding SP-A, SP-B, SP-C, and SP-D in control $(C)$ and IUGR $(I)$ rat lungs. For each postnatal day, the results were expressed and plotted as percent of $\beta$-actin. Bars are means \pm SEM $(n=3-5)$. Lung SP-A, SP-B, SP-C, and SP-D mRNA expressions measured with RT-PCR were similar between control and IUGR rats during the study period.

during the postnatal period, whereas the expression of different surfactant protein genes were not affected.

Maternal undernutrition during late gestation is associated with poor maternal weight gain and reduced fetal body weight in rats $(13,21)$. IUGR caused by placental insufficiency in sheep reveals similar findings $(22,23)$. In this study, we found that maternal undernutrition during the last week of pregnancy reduced maternal body weight and neonatal body weight, lung weight, and lung volume in the postnatal period. When adjusted for body weight, the lung weight and lung volume were significantly lower in IUGR rats than in control rats. Although the experimental dams were immediately switched back to 


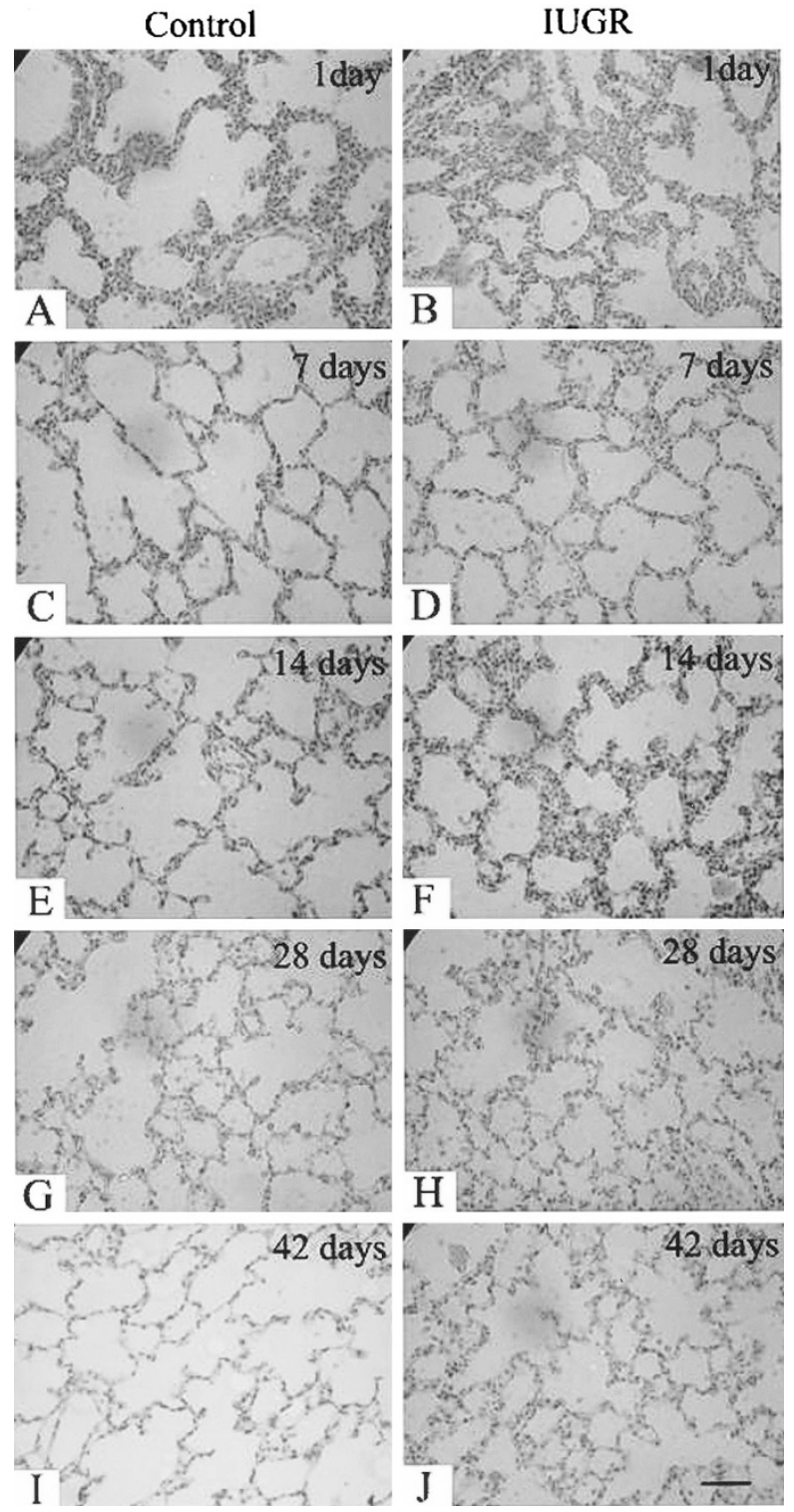

Figure 5. Light micrographs of lung sections stained with hematoxylin and eosin from control $(A, C, E, G, I)$ and IUGR $(B, D, F, H, J)$ rats during the study period. (Original magnification: $\times 400$ ). Alveolar wall thickness becomes progressively thinner as rats aged in both groups. Alveolar airspace areas were smaller in IUGR rats during the study period. Bar, $300 \mu \mathrm{m}$.

standard rat chow after delivery, they nourished their offspring till $4 \mathrm{wk}$ of age. This consequence means that newborn rats received insufficient nutrient in the postnatal period and this event could partly contribute to the differences of body weight between older control and IUGR rats.

Pulmonary surfactant is composed of approximately $90 \%$ lipids and $10 \%$ proteins, which function to stabilize the lung by producing a surface-active monolayer at the air-liquid interface of the terminal airways. The surface activity properties are primarily due to dipalmitoyl phosphatidylcholine, which comprises approximately $45 \%$ of surfactants by weight. Relatively few studies have examined the effect of maternal undernutrition on the development of the lung surfactant system in postnatal animal models. In this study, we found that total saturated phosphatidylcholine content in the lung was higher
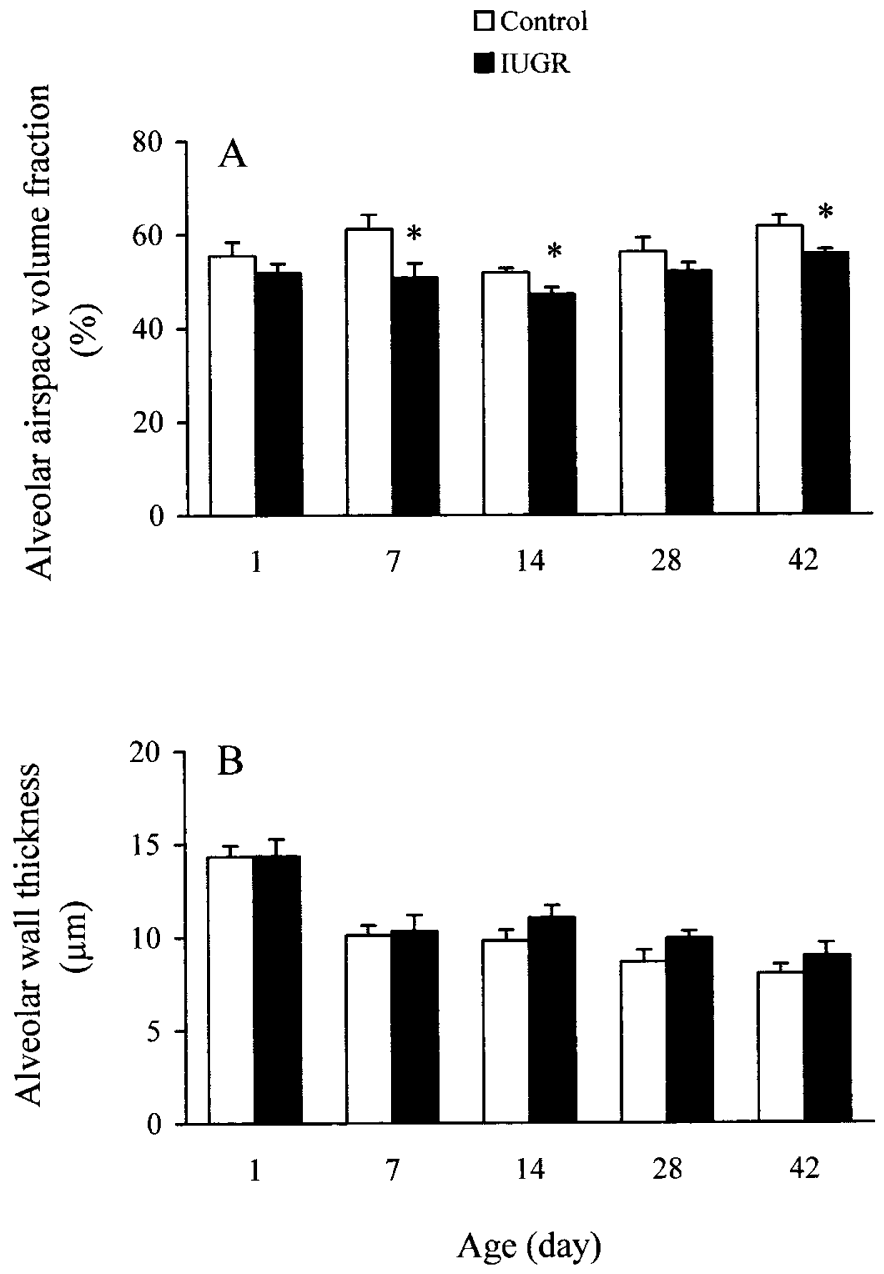

Figure 6. Changes in $(A)$ volume fractions of the alveolar airspace and $(B)$ alveolar wall thickness as a function of postnatal age for control and IUGR rats. Bars are means \pm SEM $(n=6-8)$. Volume fractions of the alveolar airspace were lower in IUGR rats, and values reached statistical significance on postnatal d 7, 14, and $42(* p<0.05)$. Alveolar wall thickness was comparable between control and IUGR rats.

on postnatal d 1 than at any other age and fell as rats aged in both study groups. These results are compatible with the generalization that total lung surfactant pools are higher at term birth than at any other time in an animal's life (24). Total saturated phosphatidylcholine contents were lower in IUGR rats' lungs and the value reached statistical significance on postnatal d 1 only. These results are in agreement with the findings of Lechner et al. $(11,21)$, who found that prenatal starvation reduces total lung saturated phospholipids in fetal and term guinea pigs at birth. Ryan et al. (25) administered LDL intravenously over $3 \mathrm{~h}$ to pregnant rats, and found that saturated phosphatidylcholine content is increased in fetal alveolar pretype II cells. In this study, we found that the differences in total lung saturated phosphatidylcholine content between control and IUGR rats became smaller as rats get older. Based on these findings, we speculated that lower lung saturated phosphatidylcholine content in IUGR rats is possibly due to reduced fatty acid substrates for the biosynthesis of phosphatidylcholine and that this effect recovers gradually when the dams were switched back to standard rat chow after delivery. 

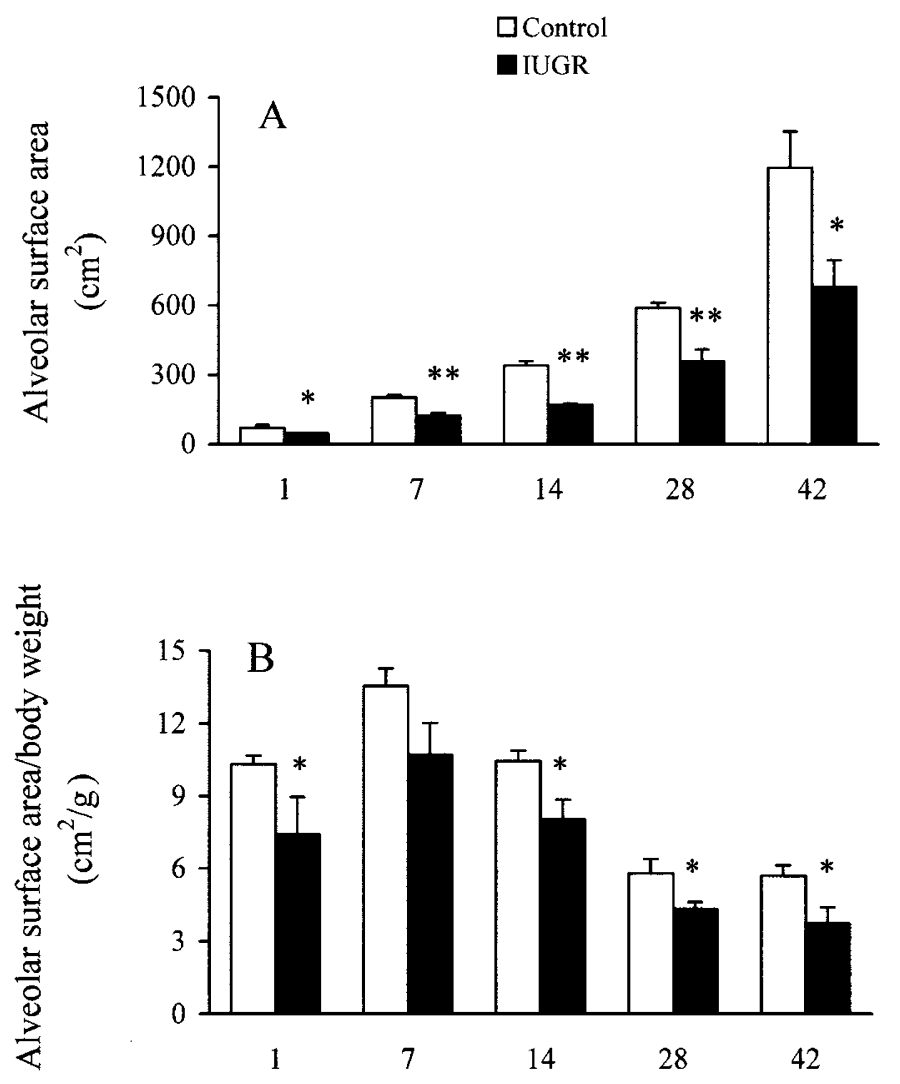

Age (day)

Figure 7. Changes in $(A)$ alveolar surface area and $(B)$ alveolar surface area/body weight ratio as a function of postnatal age for control and IUGR rats. Bars are means $\pm \operatorname{SEM}(n=6-8)$. The alveolar surface area increased as rats aged, and values were significantly lower in IUGR rats during the study period $\left({ }^{*} p<0.05,{ }^{* *} p<0.01\right)$. The alveolar surface area/body weight ratio reached a peak on postnatal d 7 and decreased as rats aged in control and IUGR rats, and values were significantly lower in IUGR rats on postnatal d 1, 14, 28, and $42(* p<0.05)$.

In this study, changes in plasma corticosterone levels during the postnatal period in control rats were similar to those reported by Henning (26). The changing pattern was parallel to the growth curve of rat adrenal glands that had a decline for the first week followed by a rise beginning on postnatal $\mathrm{d} 8$, attaining a maximum on postnatal d 25 (27). Lesage et al. (13) reported that maternal undernutrition during late gestation induces both IUGR and an overexposure of fetuses to maternal corticosterone, which disturbs the hypothalamo-pituitary adrenal axis. Plasma corticosterone concentration and total lung saturated phosphatidylcholine content were significantly lower in IUGR rats compared with control rats on postnatal d 1 only. These data indicate suppression of the expected postnatal increase in corticosterone and negative feedback control exerted by high maternal corticosterone in IUGR rats and there is dissociation between lung surfactant lipid levels resulting from IUGR and endogenous corticosterone levels. Jobe et al. (28) found that intra-amniotic endotoxin injection enhances lung maturation and does not alter cord cortisol levels in preterm lambs. These results suggest that there are other potential lung maturation factors. Glucocorticoid may stimulate choline- phosphate cytidylyltransferase activity and increase phosphatidylcholine synthesis in fetal rat lung; antenatal glucocorticoid treatment promotes lung structural maturation in preterm lambs $(29,30)$. However, the incorporation of precursor substrates such as glucose, lactate, and palmitate into fetal lung phospholipids was reduced in maternal fasting during late gestation (31). Based on these findings, we suggest that precursor substrate supplement is more important than glucocorticoid in enhancing lung maturation.

Four lung-specific proteins (SP-A, SP-B, SP-C, and SP-D) have been found to be associated with the surfactant (32). They are synthesized primarily by alveolar type II cells or bronchiolar epithelial cells, and are required both for the transition between lamellar bodies and tubular myelin as well as for the spreading of tubular myelin components to the surface film (33). Schellhase et al. (34) investigated the ontogeny of SP-A, SP-B, and SP-C mRNA in the developing rat lung and speculated that genes for surfactant proteins may be differentially regulated. The effects of maternal undernutrition on SP gene expression in postnatal lung tissues are not well characterized and are inconsistent in the literature. Gagnon et al. (35) reported that asymmetric fetal growth restriction caused by chronic placental damage (110-130 d' gestation) was associated with a significant increase in SP-A and SP-B mRNAs in fetal lamb lung. Cock et al. (36) found, to the contrary, that IUGR caused by umbilicoplacental embolization (120-140 d gestation) had no significant effects on the expression of SP-A, SP-B, and SP-C mRNA. The discrepancy between the results of those studies may be due to the differences in the etiology, severity, and gestational timing of IUGR. Observing an extensive period of umbilicoplacental embolization (120-146 d gestation), Joyce et al. (23) found that IUGR lambs have similar SP-A and SP-C mRNA levels but higher SP-B mRNA levels as compared with control lambs at 8 wk after birth. In this study, we describe for the first time the ontogeny of surfactant protein mRNA in the postnatal rat lung after maternal undernutrition during late gestation. The results of our study showed that maternal undernutrition did not affect the gene expressions of SP-A, SP-B, SP-C, and SP-D in the offspring's lung. Therefore, we suggest that IUGR does not accelerate pulmonary maturation and that surfactant proteins and surfactant lipids are regulated by separate metabolic pathways.

Alveolarization occurs predominantly within the first $2 \mathrm{wk}$ of postnatal life in rats. Therefore, the term "alveoli" correspond to "saccules" for rats younger than 2 wk old in this study. In the present study, we found that IUGR rats exhibited a significantly lower volume fraction of airspace on postnatal d 7, 14, and 42 and that the alveolar surface area and alveolar surface area/body weight ratio were significantly lower in IUGR rats as compared with control rats. These morphometric changes were consistent with the observations of Maritz et al. (37), who found that in lambs fetal growth restriction induced by umbilico-placental embolization causes smaller airspace volume density at $8 \mathrm{wk}$ after birth. Our data showed that maternal undernutrition during late gestation resulted in morphometric changes similar to those observed after the antenatal administration of dexamethasone as reported by Okajima et al. 
(38). These results further support that maternal undernutrition during late gestation increases the fetal exposure to maternal glucocorticoids (13). The findings of this study showed that changes in the volume fraction of the airspace and alveolar wall thickness during the first $21 \mathrm{~d}$ of life in control rats were similar to those observed by Burri et al. (12). Restricting calorie in adult mice reduces the alveolar surface area, whereas refeeding them fully reverses this change (39). Decreased alveolar surface area causes decreased lung compliance and increased resistance. These data suggest that decreased alveolar surface area is one of the major factors that impairs pulmonary function in IUGR infants and children.

In conclusion, the results of this study showed that maternal undernutrition during late gestation decreased lung surfactant lipid levels in the immediate postnatal period and altered lung structural development during the postnatal period, but that the expression of various surfactant protein genes in postnatal rat lungs were not changed by maternal undernutrition. These results suggest that alteration of lung surfactant and structure may be important in the pathogenesis of impaired pulmonary function in IUGR infants and children. Because pulmonary function is a long-term predictor for overall survival rates in the general population (40), we contend that physicians should attempt to manage conditions that predispose the developing fetus to reduced growth, thereby decreasing the potential risk of giving birth to an IUGR newborn.

\section{REFERENCES}

1. Tyson JE, Kennedy K, Broyles S, Rosenfeld CR 1995 The small for gestational age infant: accelerated or delayed pulmonary maturation? Increased or decreased survival? Pediatrics 95:534-538

2. Bernstein IM, Horbar JD, Badger GJ, Ohisson A, Golan A 2000 Morbidity and mortality among very-low-birth-weight neonates with intrauterine growth restriction. Am J Obstet Gynecol 182:198-206

3. Rona RJ, Gulliford MC, Chinn S 1993 Effects of prematurity and intrauterine growth on respiratory health and lung function in childhood. BMJ 306:817-820

4. Barker DJ, Godfrey KM, Fall C, Osmond C, Winter PD, Shaheen SO 1991 Relation of birth weight and childhood respiratory infection to adult lung function and death from chronic obstructive airways disease. BMJ 303:671-675

5. Stein CE, Kumaran K, Fall CH, Shaheen SO, Osmond C, Barker DJ 1997 Relation of fetal growth to adult lung function in South India. Thorax 52:895-899

6. Creasy RK, Resnik R 1994 Intrauterine growth restriction. In: Creasy RK, Resnik R (eds) Maternal-Fetal Medicine. WB Saunders, Philadelphia, pp 558-574

7. Gagnon R, Challis J, Johnston L, Fraher L 1994 Fetal endocrine responses to chronic placental embolization in the late-gestation ovine fetus. Am J Obstet Gynecol 170:929-938

8. Nicolaides KH, Economides DL, Soothill PW 1989 Blood gases, pH, and lactate in appropriate- and small-for-gestational-age fetuses. Am J Obstet Gynecol 161:9961001

9. Merrill JD, Ballard RA 1998 Antenatal hormone therapy for fetal lung maturation. Clin Perinatol 25:983-997

10. Massaro D, Massaro GD 1997 Regulation of the architectural development of the lung. In: Crystal RG, West JB, Weibel ER, Barnes PJ (eds) The Lung: Scientific Foundations, 2nd Ed. Lippincott-Raven, Philadelphia, pp 1027-1034

11. Lechner AJ, Winston DC, Bauman JE 1986 Lung mechanics, cellularity, and surfactant after prenatal starvation in guinea pigs. J Appl Physiol 50:1610-1614

12. Burri PH, Dbaly J, Weibel ER 1974 The postnatal growth of the rat lung. I. Morphometry. Anat Rec 178:711-730
13. Lesage J, Blondeau B, Grino M, Bréant B, Dupouy JP 2001 Maternal undernutrition during late gestation induces fetal overexposure to glucocorticoids and intrauterine growth retardation, and disturbs the hypothalamo-pituitary adrenal axis in the newborn rat. Endocrinology 142:1692-1702

14. Scherle W 1970 Simple method for volumetry of organs in quantitative stereology. Mikroskopie 26:57-60

15. Bligh EG, Dyer WJ 1959 A rapid method of total lipid extraction and purification. Can J Biochem Physiol 37:911-917

16. Barlett GR 1959 Phosphorous assay in column chromatography. J Biol Chem 234:466-468

17. Mason RJ, Nellenbogen J, Clements JA 1976 Isolation of disaturated phosphatidylchioline with osmium tetroxide. J Lipid Res 17:281-284

18. Zelter TB, Bertacchini M, Messerli A, Burri PH 1990 Morphometric estimation of regional differences in the rat lung. Exp Lung Res 16:145-158

19. Bolender RP, Hyde DM, Dehoff RT 1993 Lung morphometry: a new generation of tools and experiments for organ, tissue, cell, and molecular biology. Am J Physiol 265:L521-L548

20. Weibel ER 1979 Stereological Methods, Vol 1. Academic Press, New York, pp 9-196

21. Lin Y, Lechner AJ 1991 Surfactant content and type II cell development in fetal guinea pig lungs during prenatal starvation. Pediatr Res 29:288-291

22. Maritz GS, Cock ML, Louey S, Joyce BJ, Albuquerque CA, Harding R 2001 Effects of fetal growth restriction on lung development before and after birth: a morphometric analysis. Pediatr Pulmonol 32:201-210

23. Joyce BJ, Louey S, Davey MG, Cock ML, Hooper SB, Harding R 2001 Compromised respiratory function in postnatal lambs after placental insufficiency and intrauterine growth restriction. Pediatr Res 50:641-649

24. Ohashi T, Pinkerton K, Ikegami M, Jobe AH 1994 Changes in alveolar surface area, surfactant protein A, and saturated phosphatidylcholine with postnatal rat lung growth. Pediatr Res 35:685-689

25. Ryan AJ, Medh JD, McCoy DM, Salome RG, Mallampalli RK 2002 Maternal loading with very low-density lipoproteins stimulates fetal surfactant synthesis. Am J Physiol 283:L310-L318

26. Henning S 1978 Plasma concentrations of total and free corticosterone during development in the rat. Am J Physiol 4:E451-E456

27. Bartova A 1968 Functioning of the hypothalamo-pituitary-adrenal system during postnatal development in rats. Gen Comp Endocrinol 10:235-239

28. Jobe AH, Newnham JP, Willet KE, Moss TJ, Ervin MG, Padbury JF, Sly P, Ikegami M 2000 Endotoxin-induced lung maturation is preterm lambs is not mediated by cortisol. Am J Respir Crit Care Med 162:1656-1661

29. Post M, Barsoumian A, Smith BT 1986 The cellular mechanism of glucocorticoid acceleration of fetal lung maturation. Fibroblast-pneumonocyte factor stimulates choline-phosphate cytidylyltransferase activity. J Biol Chem 261:2179-2184

30. Willet KE, Jobe AH, Ikegami M, Kovar J, Sly PD 2001 Lung morphometry after repetitive antenatal glucocorticoid treatment in preterm sheep. Am J Respir Crit Care Med 163:1437-1443

31. Rhoades RA, Ryder DA 1981 Fetal lung metabolism. Response to maternal fasting. Biochim Biophys Acta 663:621-629

32. Hawgood S, Schiffer K 1991 Structures and properties of the surfactant-associated proteins. Annu Rev Physiol 53:375-394

33. Hawgood S, Benson BJ, Halmilton Jr RL 1985 Effects of a surfactant-associated protein and calcium ions on the structure and surface activity of lung surfactant lipids. Biochemistry 24:184-190

34. Schellhase DE, Emrie PA, Fisher JH, Shannon JM 1989 Ontogeny of surfactant apoproteins in the rat. Pediatr Res 26:167-174

35. Gagnon R, Langride J, Inchley K, Murotsuki J, Possmayer F 1999 Changes in surfactant-associated protein mRNA profile in growth-restricted fetal sheep. Am J Physiol 276:L459-L465

36. Cock ML, Albuquerque CA, Joyce BJ, Hooper SB, Harding R 2001 Effects of intrauterine growth restriction on lung liquid dynamics and lung development in fetal sheep. Am J Obstet Gynecol 184:209-216

37. Maritz GS, Cock ML, Louey S, Joyce BJ, Albuquerque CA, Harding R 2001 Effects of fetal growth restriction on lung development before and after birth: a morphometric analysis. Pediatr Pulmonol 32:201-210

38. Okajima S, Matsuda T, Cho K, Matsumoto Y, Kobayashi Y, Fujimoto S 2001 Antenatal dexamethasone administration impairs normal postnatal lung growth in rats. Pediatr Res 49:777-781

39. Massaro GD, Radaeva S, Clerch AB, Massaro D 2002 Lung alveoli: endogenous programmed destruction and regeneration. Am J Physiol 283:L305-L309

40. Schünemann HJ, Dorn J, Grant BJB, Winkelstein W, Trevisan M 2000 Pulmonary function is a long-term predictor of mortality in the general population. Chest 118:656-664 